\author{
Contato: \\ Rua Tiradentes, 380 - apto. 303 \\ 38400200 - Uberlândia - Minas Gerais \\ E-mail: mlmhistor@hotmail.com
}

\section{ORVILLE ADELBERT DERBY: \\ NOTAS PARA O ESTUDO DE SUA ATUAÇÃO CIENTÍFICO- INTELECTUAL EM SÃO PAULO $(1886-1905)^{\prime}$}

\section{Marcelo Lapuente Mahl}

Universidade Federal de Uberlândia

\title{
Resumo
}

Entre os anos de 1886 e 1905, o geólogo norte-americano Orville Adelbert Derby chefiou a Comissão Geográfica e Geológica da Província de São Paulo, criada pelo governo paulista como forma de favorecer, por meio do conhecimento científico do território, a expansão agrícola que naquele momento seguia o ritmo crescente da economia cafeeira. Ao mesmo tempo, Derby também se envolveu diretamente, no ano de 1894, no processo de criação do Instituto Histórico e Geográfico de São Paulo, que reuniu, no final do século XIX, grupos ligados às elites intelectuais do estado interessados em construir uma história regional que destacasse o papel de São Paulo no cenário nacional. Este artigo analisa essa dupla atuação de Orville Adelbert Derby, que ocupou espaços importantes na vida social, científica e intelectual paulista, tanto como geólogo, quanto como pesquisador da historia regional.

\section{Palavras-chave}

Ciência - vida intelectual - mito bandeirante.

1 Projeto "Orville Adelbert Derby: ciência e vida intelectual em São Paulo (1886-1905)", financiado pela Pró- Reitoria de Pesquisa e Pós Graduação (PROPP), da Universidade Federal de Uberlândia. 


\author{
Contact: \\ Rua Tiradentes, 380 - apto. 303 \\ 38400200 - Uberlândia - Minas Gerais \\ E-mail: mlmhistor@hotmail.com
}

\section{ORVILLE ADELBERT} DERBY:

NOTES FOR THE STUDY

OF HIS INTELLECTUAL-

SCIENTIFIC PERFORMANCE

IN THE STATE OF SÃO

PAULO (1886-1905)

\author{
Marcelo Lapuente Mahl \\ Universidade Federal de Uberlândia
}

\begin{abstract}
From 1886 to 1905, North-American geologist Orville Adelbert Derby led the Geographical and Geological Commission in the Province of São Paulo, created by the government of the state as a way of assisting, through the scientific knowledge of the territory, the agricultural expansion which at that moment had been following the growing pace of coffee based economy. At the same time, Derby also got involved directly, in the year of 1894, in the process of creating the Historical and Geographical Institute of São Paulo, which gathered, in the end of $19^{\text {th }}$ century, groups linked to the intellectual elites in the state which were interested in writing a regional story that was successful in highlighting the important participation of São Paulo in the national scenario. This article analyzes Orville Adelbert Derby's double performance, who occupied important spaces in social, scientific and intellectual lives in the state of São Paulo, both as a geologist and as a regional history researcher.
\end{abstract}

\title{
Keywords
}

Science - intellectual life - bandeirante myth. 
REVISTA DE HISTÓRIA SÃO PAULO, N ${ }^{\circ} 167$, p. 295-320,

JULHO / DEZEMBRO 2012
MARCELO LAPUENTE MAHL

Orville Adelbert Derby: notas para o estudo de sua atuação científico-intelectual em São Paulo (1886-1905)

Na região central da cidade do Rio de Janeiro, em fins do século XIX, localizava-se, na avenida $1^{\circ}$ de março, em frente à praça José de Alencar, um dos hotéis mais luxuosos do país, o hotel dos Estrangeiros. Servido, a cada dois minutos, pelos bondes da Cia. Jardim Botânico, segundo o material de divulgação do estabelecimento, o hôtel des Etrangers oferecia conforto aos abastados que procuravam hospedagem na capital da jovem República. Possuía itens necessários para satisfazer os sonhos de modernidade próprios do período, com salous, salons de lecture, billard, salles pour banquets, além de bains chauds et froids. A cozinha, ainda segundo o anúncio, era excellente - Les personnes malades auront une cuisine spéciales, d'accord avec les prescriptions du médecin. E, obviamente, mantinha uma hygiène parfaite, para a felicidade dos higienistas e médicos da época. ${ }^{2}$ Sãos e enfermos podiam assim desfrutar da civilização aqui mesmo, nos trópicos, realizando, no hotel, o simulacro brasileiro da Bèlle Époque, que prometia satisfazer os caprichos até dos hóspedes mais requintados.

Porém, esse espaço de festas, encontros políticos e sonhos de civilização foi palco também de acontecimentos menos civilizados, como o assassinato de Pinheiro Machado, um dos mais influentes políticos da República, em pleno saguão do hotel, em setembro de 1915.

Dois meses depois do assassinato do senador gaúcho, outra ocorrência macabra surpreendeu os meios intelectuais cariocas e paulistas. O geólogo Orville Adelbert Derby, após passar a noite em um jantar agradável na casa de amigos, segundo relato do compatriota J. C. Branner (1922), suicidou-se com um tiro na cabeça, sendo encontrado pelo mensageiro do hotel ainda com a arma presa à mão, em 27 de novembro de 1915. Segundo o relato de Branner, os jornais da época definiram o suicídio de Derby como uma "grande perda nacional". Entretanto, tal demonstração de respeito e solidariedade parece ter vindo com atraso, uma vez que Derby vinha enfrentando uma série de dificuldades políticas para manter suas atividades no Serviço Geológico e Mineralógico, sediado na capital federal. Aparentemente, os dissabores dos embates políticos, muitos dos quais travados publicamente nas páginas dos jornais fluminenses, levaram ao ato extremo do suicídio, encerrando a vida deste norte-americano que viveu sessenta e quatro anos, quarenta deles transcorridos no Brasil.

\footnotetext{
2 O anúncio e outros documentos referentes ao Rio de Janeiro do século XIX podem ser acessados no site: www.rioquepassou.com.br. Acesso em 2/10/ 2011.
} 
Não foi a primeira vez que Orville A. Derby enfrentou dificuldades para manter suas atividades profissionais no país. No começo do século XX, quando então chefiava a Comissão Geográfica e Geológica de São Paulo, ele se envolveu em uma disputa, inicialmente de ordem científica, com professores da Escola Politécnica paulistana. O embate afetou a posição de liderança do norte-americano, o que culminou em seu afastamento da Comissão em janeiro de 1905 (Figuerôa, 1997). Encerravam-se, então, 19 anos de trabalhos e atuação destacada nos meios intelectuais paulistas, não somente no que se referia a sua área específica de competência - a geologia - como também em outras esferas do saber, como a história, a etnografia e a geografia, pluralidade que revela a diversidade de interesses que envolveram a produção científica de Derby.

Produção científica plural, como era própria dos intelectuais de seu tempo. Com poucas instituições acadêmicas consolidadas no Brasil, ao longo do século XIX, era comum esse espírito multifacetado, de homens que buscavam em um autodidatismo abarcar conhecimentos de toda ordem, transitando livremente entre saberes tão díspares quanto a história, as ciências naturais e a etimologia. Nesse espaço de trânsito intelectual possível, pelo menos até o início do século XX, indivíduos com conhecimentos técnicos, em áreas específicas, como era o caso de Orville Derby, capacitavam-se com um capital simbólico ${ }^{3}$ - no caso, ter passado por uma instituição acadêmica

\footnotetext{
3 A expressão capital simbólico será aqui utilizada seguindo as reflexões do sociólogo Pierre Bourdieu, que, ao longo de sua longa trajetória intelectual, se dedicou a pensar, entre vários e complexos objetos de análise, os fenômenos sociais a partir de dois conceitos principais: campo e habitus. Compreende-se então o campo como um espaço social hierarquizado, construído por agentes específicos que, determinando regras e fronteiras de atuação e inclusão, acabam por delimitar uma área em que os seus membros disputam tanto capital material (dinheiro, propriedades, bens materiais) quanto capital simbólico (prestígio e distinção social, honrarias, deferência). O habitus, por sua vez, é aquilo que foi incorporado pelo sujeito, a partir de sua experiência na dinâmica social do campo. O habitus pode ser compreendido como as diversas formas de perceber o mundo, de agir socialmente, de avaliar a experiência social, e que, estando intimamente atrelado ao campo, acaba por dinamizá-lo e ordená-lo. Dessa forma, o capital simbólico é o que oferece distinção e reconhecimento dentro de um determinado campo; é o que permite ascender dentro de um espaço social delimitado, oferecendo retorno, material ou simbólico, nas relações de poder que se estabelecem entre os que aceitam as regras desse intrincado jogo. No caso específico deste artigo, compreende-se que Orville Adelbert Derby estava inserido em dois campos distintos, que muitas vezes se entrecruzavam e se relacionavam. Primeiramente, no científico, e seu capital simbólico principal estava fundamentado nos conhecimentos geológicos adquiridos em uma instituição de ensino já consagrada; e, em segundo lugar, no campo intelectual paulista. Neste, é certo que ocorreu uma reconversão de capital, isto é, seus conhecimentos acadêmicos favoreceram sua admissão neste novo campo
} 
respeitável - o que dava credibilidade a suas afirmações, mesmo em áreas dessemelhantes (Gomes, 1986).

No Brasil, a partir de meados do século XIX, algumas poucas instituições capacitavam essas elites nacionais, em meio ao grande número de analfabetos e dos espaços limitados de atuação acadêmica e intelectual. Em São Paulo, a Academia de Direito, fundada em 1827, no mesmo período que sua congênere, em Olinda, foi a mais destacada dessas instituições, berço de políticos e literatos que marcaram profundamente a vida intelectual brasileira. Outras instituições nacionais, fundadas no início do século XIX, como as academias médicas do Rio de Janeiro e da Bahia, continuaram, ao longo de sua história, qualificando, de forma proeminente, os quadros das elites dirigentes. Também merece destaque a fundação, em 1874, da Escola Politécnica do Rio de Janeiro e, um ano depois, o início das atividades de Escola de Minas de Ouro Preto; esta, em especial, tentando suprir a ausência de engenheiros no Brasil.

Tais instituições possibilitaram a formação de juristas, engenheiros e médicos em território nacional. Homens de ciências, mas também homens de letras, que acabaram imersos no universo das humanidades e que encontraram, nas salas dos institutos históricos e geográficos, o local mais propício para a divulgação e afirmação dessa produção diletante. A pesquisa histórica foi particularmente porosa em relação a este tipo de produção não profissionalizada, sendo o historiador típico do século XIX um "homem erudito, que transitava, com fluência, por diferentes domínios intelectuais" (Ferreira, 2002, p. 123).

Os institutos históricos foram repositórios privilegiados dessa produção plural, e o Instituto Histórico e Geográfico Brasileiro, fundado em 1838, o primeiro dessas agremiações no Brasil, tornou-se um espaço de construção de uma história nacional que destacava o papel da Corte carioca no processo de consolidação do estado monárquico brasileiro. Historiadores, literatos e

que, na virada do século XIX, se formava, congregando membros das elites econômicas letradas, em locais como o Instituto Histórico e Geográfico de São Paulo, ou nos salões privados das famílias mais abastadas. Sérgio Miceli (2001) já demonstrou de que maneira, no mesmo período, se gestava no país um incipiente, mas ainda pouco autônomo, campo intelectual, revelando as estratégias de inclusão e distinção utilizadas por vários literatos nacionais. Em São Paulo, Derby insere-se nessas disputas e esforços que levaram à formação de um campo intelectual, e tanto seus conhecimentos técnicos quanto sua circulação privilegiada nos meios intelectuais da capital do estado ajudam a compreender sua desenvolta e plural trajetória, entre os anos de 1886 e 1905. Sobre os conceitos aqui apresentados de campo e habitus consultar, entre outras obras do mesmo autor: BOURDIEU, Pierre. As regras de arte. São Paulo: Cia das Letras, 2002; BOURDIEU, Pierre. A distinção - crítica social do julgamento. São Paulo: Edusp, 2008. 
políticos passaram pela agremiação carioca, que tornou-se um dos locais de maior prestígio social e intelectual do país, ao longo do Segundo Reinado (Guimaraes, 1988; Schwarcz, 2007).

Seguindo o exemplo do IHGB, outras agremiações surgiram no Brasil, mantendo o padrão de procura por uma história nacional, mas buscando as especificidades e contribuições regionais para a história pátria. Nesse sentido, Lilia Moritz Schwarcz (1993) destaca a fundação do Instituto Archeologico e Geographico Pernambucano em 1862, e a fundação, em 1894, do Instituto Histórico e Geographico de São Paulo. Especificamente sobre a produção intelectual realizada pelo instituto paulista, Antonio Celso Ferreira (2002) ressalta o caráter regional da casa, que procurou consolidar uma visão positiva sobre $o$ povo e a história de São Paulo, construindo, nas páginas de sua revista, uma epopeia grandiosa que misturou, como um calidoscópio, ciência e literatura, com resultados apologéticos de amplo alcance político, cultural e social. ${ }^{4}$

O surgimento e a consolidação dessas novas iniciativas de produção científica e cultural, materializadas nos museus dedicados às ciências naturais, nas faculdades e institutos históricos, facilitou a formação de uma crescente rede de intelectuais, tanto nacionais quanto estrangeiros, que transitavam em vários campos do saber e que encontraram, nesses locais únicos, não raramente financiados pelo Estado, espaços de atuação e de discussão sobre assuntos que extrapolavam a esfera científica, versando sobre literatura, artes visuais e projetos para a nação.

A chegada de d. João VI ao Brasil, em 1808, marcou esse momento de formação das primeiras instituições de pesquisa e ensino no país, objetivando fornecer quadros capazes de sustentar as demandas administrativas, sociais, políticas e burocráticas da nova sede do Império português. Como afirma Lilia Moritz Schwarcz (1993), "Data dessa época a instalação dos primeiros estabelecimentos de caráter cultural, como a Imprensa Régia, a Biblioteca, o Real Horto e o Museu Real" (p. 23). Em relação às instituições de pesquisa, aquelas voltadas para as ciências naturais tiveram um amplo crescimento, resultado do prestígio que as ciências naturais, especialmente a biologia, desfrutavam no ambiente intelectual do século XIX, tornando-se

\footnotetext{
4 Sobre organização e os componentes ideológicos dos vários institutos históricos criados no Brasil, ao final do século XIX, ver: Dossiê 1: Os institutos históricos e geográficos. Revista Patrimônio e Memória. Cedap, vol. 7, n 1, junho de 2011. Disponível em: www.cedap.assis.unesp.br
} 
um paradigma explicativo para o mundo, que extrapolou as frágeis fronteiras científicas, influenciando sobremaneira as ciências humanas. ${ }^{5}$

É importante ressaltar que os museus e institutos históricos fundados por todo o Brasil, ao longo do século XIX, cumpriram pelo menos dois objetivos primordiais durante o Segundo Reinado, época de formação e consolidação de várias dessas agremiações. Primeiramente, o modernizador, que buscava inserir o país nos caminhos da pesquisa internacional, principalmente nas áreas de ciências naturais, tentando superar uma condição periférica que, até então, reservara à nação somente o papel de fornecedora de material de pesquisa bruto para suprir o desejo das inúmeros naturalistas ${ }^{6}$ que, cada vez mais, por aqui aportavam. Por outro lado, coube também aos museus e institutos o papel de guardiões da história e do orgulho nacional, reservando para si um status simbólico de defensores da nacionalidade, efetivando o projeto de nação - uma monarquia esclarecida nos trópicos - incorporado, de forma convincente e alegórica, na figura de d. Pedro II.

\footnotetext{
5 A influência das ciências naturais, mais especificamente da biologia, nas ciências humanas, foi amplamente discutida por Michel Foucault, em vários momentos de sua vasta e complexa obra. Mais precisamente no livro As palavras e as coisas (1987), Foucault pensa a formação das especificidades e conceitos próprios das ciências humanas a partir de movimentos de aproximação e afastamento em relação aos modelos oferecidos pela biologia, economia e filologia. Da biologia, as ciências humanas construíram, segundo o autor, uma compreensão do homem "enquanto um ser que tem funções - que recebe estímulos (fisiológicos, mas também sociais, inter-humanos, culturais), que responde a eles, que se adapta, evolui, submete-se às exigências do meio, harmoniza-se com as modificações que ele impõe, busca apagar os desequilíbrios, age segundo regularidades, tem, em suma, condições de existência e a possibilidade de encontrar normas médias de ajustamento que lhe permitem exercer suas funções" (p. 374). A filósofa Hannah Arendt (1998) também aponta para o nascimento, nas relações entre as ciências naturais e as ciências humanas, do pensamento racial, que influenciou demasiadamente diferentes campos do saber no mundo ocidental, ao longo do século XIX.

6 A expressão naturalista é usada de forma genérica para designar os que exerciam as atividades ligadas às ciências naturais, uma vez que mesmo os campos específicos destas ciências, como a botânica ou a zoologia, ainda estavam em pleno processo de demarcação de fronteiras internas, ou de especialização. A própria constituição plural dos museus e institutos do século XIX, publicando trabalhos de várias áreas do conhecimento, revelam esse momento de hibridismo teórico. Neste sentido, afirma Maria Margaret Lopes (1997), que “Ciências como a Paleontologia, Arqueologia, Etnografia, Antropologia ocuparam papéis de destaque nas discussões da época, apelando à memória, à origem, à civilização, à construção de identidades imaginárias. Foi difícil ao espírito positivista do final do século XIX decidir qual ciência se encarregaria, por exemplo, do estudo dos fósseis, ou de traçar a linha demarcatória entre ossos e fósseis de animais e humanos. E estes domínios, partilhados entre as ciências da terra e da vida, tornaram-se ainda mais complexos com a intromissão das ciências humanas" (p. 71).
} 
Com o surgimento dessas instituições de pesquisa, inúmeros estrangeiros estiveram em território nacional, não raro recebendo apoio desses museus e hortos florestais recém-formados. ${ }^{7}$ Outros continuavam participando de expedições de coleta, fornecendo todo tipo de material de pesquisa - principalmente plantas e animais -, às instituições estrangeiras, sempre ávidas por novidades vindas dos trópicos. Neste caso, o próprio Museu Real do Rio de Janeiro, fundado em 1818, e que pode ser considerado um marco no processo de institucionalização das ciências naturais no Brasil, serviu como fornecedor de material para uma série de museus europeus, seguindo um direcionamento bastante comum na Europa da Ilustração, que estimulava a existência de museus centrais abastecidos por uma rede de museus periféricos. No Brasil, a fundação do Museu Real respondeu não somente aos projetos de modernização científica, como também à necessidade de criar uma instituição centralizadora das pesquisas na área de ciências naturais. Para lá deveriam afluir as coleções recebidas de todo o reino, para catalogação, exposição e possíveis envios para o exterior (Lopes, 1997).

Ainda segundo Margaret Lopes, o Museu Real, posteriormente rebatizado como Museu Nacional, teve um papel preponderante no desenvolvimento das pesquisas em ciências naturais, mantendo relações com instituições internacionais, como a Real Academia de Ciências de Lisboa e o Royal Botanic Gardens, da Inglaterra; além de vínculos com instituições pátrias, como o Instituto Histórico e Geográfico Brasileiro ou o Jardim Botânico. Pelo museu passaram figuras que contribuíram definitivamente para o desenvolvimento da pesquisa científica no Brasil, durante o século XIX, como Frederico Leopoldo César Burlamaque, Francisco Freire Alemão e Ladislau de Sousa Melo Neto. Além dos pesquisadores nacionais, naturalistas de vários países utilizaram as coleções do Museu. Neste sentido, vale destacar a passagem do naturalista Louis Agassiz que, em 1865, chegou ao Brasil em meio a uma disputa teórica com Charles Darwin, com quem debatia a respeito da validade, ou não, da teoria da evolução, exposta por Darwin em 1859 no livro A origem das espécies (Freitas, 2002).

\footnotetext{
Seguindo o caminho aberto pelo Museu Nacional, fundado em 1818, surgiram, ao longo de 1840 e 1850, o Gabinete de História Natural da Bahia e o Gabinete de História Natural do Maranhão. Também se destaca o Museu Paraense Emilio Goeldi (1866) e o Museu Paulista (1894). Todos atuando de forma efetiva para a institucionalização das ciências naturais no Brasil (LOPES, 1997; DANTES, 2001; SCHWARCZ, 1993; HEIZER, VIDEIRA; 2001).
} 
Outros viajantes estenderam sua estada pelo Brasil, ocupando cargos administrativos no Museu Nacional, como Emílio Goeldi e Hermann Von Ihering. Estes dois, em especial, acabaram dirigindo outras duas instituições que contribuíram, de forma direta, para o fortalecimento das ciências naturais no país.

O suíço Emílio Goeldi assumiu, em 1894, o Museu Paraense, após alguns anos de inatividade e inércia da instituição. Com o desenvolvimento do ciclo da borracha na região Norte, o museu acabou reconquistando defensores entre a classe política, o que levou a revalorização do espaço, agora sob a direção de Goeldi. O naturalista reformulou completamente a casa, trazendo vários pesquisadores internacionais, além de lançar o Boletim do Museu Paraense de História Natural e Etnográfica, que alcançou grande prestígio entre os pesquisadores da área. Em 31 de dezembro de 1900, o governador do Pará, José Paes de Barros Carvalho, alterou o nome do Museu Paraense para Museu Goeldi. Essa homenagem em vida foi resultado não somente do reconhecimento, pelas autoridades políticas, do trabalho desenvolvido pelo naturalista como diretor, mas também devido ao destaque alcançado por ele durante o período em que assessorou o barão do Rio Branco na definição dos limites territoriais entre o Brasil e a Guiana Francesa. Ao que tudo indica, os conhecimentos de Goeldi sobre a região Norte acabaram por contribuir decisivamente para a vitória nacional perante a França, na definição do rio Oiapoque como fronteira fluvial, em 1900, como desejava o governo brasileiro (Sanjad, 2009).

Já Hermann Von Ihering, zoólogo alemão de grande prestígio internacional, assumiu, após passagem pelo Museu Nacional, a direção do Museu Paulista, em 1894, imprimindo à instituição uma forte marca administrativa, aliada ao rigor científico. A Revista do Museu Paulista também se tornou, sob a direção de Ihering, um periódico de referência, não somente nas áreas específicas das ciências naturais, com destaque para a zoologia, como também nas pesquisas etnográficas e antropológicas (Brefe, 2005). ${ }^{8}$

As atividades empreendidas pelos museus e institutos trouxeram ao Brasil dezenas de expedições de naturalistas, financiadas tanto por governos

\footnotetext{
8 A saída de Hermann Von Ihering do Museu Paulista envolveu uma polêmica bastante conhecida pela historiografia. Ele defendeu, em vários artigos publicados na imprensa paulista e carioca, o uso da força contra as tribos indígenas refratárias à "civilização", em um momento de grande expansão agrícola, o que gerava, constantemente, confrontos entre índios e colonizadores, nas regiões mais fronteiriças do estado de São Paulo (GAGLIARDI, 1989). As afirmações polêmicas, iniciadas com um artigo publicado em 1908 pela Revista do Museu Paulista, acabaram desgastando a figura de Ihering, maculando sua posição na diretoria do Museu, o que levou ao seu afastamento em 1916.
} 
REVISTA DE HISTÓRIA

SÃO PAULO, N 167, p. 295-320,

JULHO / DEZEMBRO 2012
MARCELO LAPUENTE MAHL

Orville Adelbert Derby: notas para o estudo de sua atuação cientifico-intelectual em São Paulo (1886-1905)

quanto pela iniciativa privada. Como afirma Nogueira (2000), “o século XIX foi considerado o dos naturalistas no Brasil, com a realização de expedições científicas, de norte a sul" (p. 47). Seguir os passos de alguns desses esforços coletivos, em que ciência, interesses nacionais, curiosidade intelectual e impulso desbravador se misturavam, torna-se útil para compreender o longo movimento de gestação das ciências naturais no Brasil, do qual Orville A. Derby pode ser considerado um dos mais destacados colaboradores. ${ }^{9}$

Das expedições precursoras, merece destaque a missão artística francesa, trazida por d. João VI para desenvolver atividades científicas e culturais na recém-fundada Escola Real de Ciências..$^{10}$ Dela participou, entre tantos nomes de relevo, o pintor francês Jean Baptiste Debret, que, apesar de não ser um cientista de formação, acabou, durante sua estada no país, entre os anos de 1816 e 1831, produzindo uma das mais completas descrições do

\footnotetext{
9 A geologia foi uma das áreas do conhecimento de maior interesse das expedições que chegaram ao Brasil no século XIX, devido às inequívocas implicações econômicas inerentes à atividade. Viktor Leinz (1955) dividiu a história das pesquisas geológicas no país em três momentos distintos: a primeira fase, entre os anos de 1810 e 1875, chamada de época dos viajantes, foi definida pelo autor como um momento em que as pesquisas dependiam exclusivamente dos cientistas estrangeiros que chegavam ao país; no segundo período proposto, o das comissões, criadas no país entre 1875 e 1907, encontra-se um número maior de brasileiros participando das atividades exploratórias, apesar da liderança inconteste dos estrangeiros; em uma última fase, que tem como marco a criação do Serviço Geológico e Mineralógico do Brasil, em 1907, já se observa o papel preponderante dos cientistas nacionais nas pesquisas geológicas. Essa proposta de análise, um tanto quanto esquemática, e que pode ser confrontada por trabalhos mais recentes sobre a história das ciências geológicas no Brasil, ainda ajuda a esclarecer a forte presença de Orville A. Derby em nossa vida científica e cultural, colocando-o exatamente na transição de uma ciência liderada por estrangeiros para uma ciência feita preponderantemente por mãos nativas. Nesse sentido, Viktor Leinz chega a afirmar que Derby foi "o último dos grandes pesquisadores estrangeiros e o primeiro brasileiro" (1955, p. 251). As expedições científicas apresentadas ao longo do presente texto permitem vislumbrar de forma mais clara essa possibilidade de interpretação.

${ }^{10}$ Já existe uma bibliografia bastante extensa a respeito das viagens e dos viajantes naturalistas que exploraram o Brasil ao longo do século XIX. Para as análises que agora se seguem, foram utilizadas como obras de referência, entre outras: AZEVEDO, Fernando. A cultura brasileira. Brasília: UNB, 1963; AZEVEDO, Fernando. As ciências no Brasil, v.1 e 2. São Paulo: Ed. Melhoramentos, 1955; FRANÇA, Jean Marcel Carvalho; RAMINELLI, Ronald. Andanças pelo Brasil colonial. São Paulo: Unesp, 2009; FRANÇA, Jean Marcelo Carvalho. Visões do Rio de Janeiro colonial. Rio de Janeiro: José Olympio, 2008; HEIZER, Alda, VIDEIRA, Antonio Augusto Passo. Ciência, civilização e Império nos trópicos. Rio de Janeiro: Acess, 2001; LOPES, Margaret. O Brasil descobre a pesquisa científica: os museus e as ciências naturais no século XIX. São Paulo: Hucitec, 1997; PEREIRA, João Baptista Borges; SCHADEN, Egon. Exploração antropológica. In: HOLANDA, Sérgio Buarque de. História geral da civilização brasileira. Tomo II, $3^{\circ}$ v. São Paulo/Rio de Janeiro: Difel, 1976; PINTO, Olivério M. Oliveira. Viajantes e naturalistas. In: HOLANDA, Sérgio Buarque de. História geral da civilização brasileira. Tomo II, $3^{\circ}$ v. São Paulo/Rio de Janeiro: Difel, 1976.
} 
ambiente físico, cultural, social e etnológico do Brasil do século XIX, a obra Voyage pittoresque et historique au Brésil, publicada na França entre 1831 e 1839. Outra expedição importante do período joanino foi a missão científica austro-bávara, que veio ao Brasil a convite da arquiduquesa dona Leopoldina, esposa do então príncipe d. Pedro. A viagem teve uma vocação muito mais científica que a precedente missão francesa, trazendo para o Brasil dois nomes destacados da botânica e da geologia: Johann Von Natterer e Johann Emmanuel Pohl. Também acompanhou a expedição Philip Von Martius, que desenvolveu importantes pesquisas botânicas no Rio de Janeiro, São Paulo, Minas Gerais e Maranhão. Martius viajou em companhia do zoólogo Johann Baptiste Von Spix, que desenhou centenas de pranchas com descrições pormenorizadas de diversos grupos indígenas brasileiros, além da fauna e flora regional, principalmente amazônica. Os naturalistas Spix e Martius percorreram grandes distâncias pelo interior do Brasil, de São Paulo ao Amazonas, entre os anos de 1817 e 1820. As andanças deram origem a várias publicações na Europa, mas a Flora Brasiliensis, de Martius, é uma obra única, e talvez incomparável, na arte fitográfica do século XIX.

A viagem liderada pelo alemão Langsdorff, a serviço do governo prussiano, entre os anos de 1825 e 1829, foi outra iniciativa importante no que se refere às atividades científicas e exploratórias em território brasileiro. Dela participou o desenhista Rugendas, que produziu a Voyage pittoresque dans le Brésil, publicada em Paris entre 1827 e 1835. Descrições da natureza, das tribos indígenas e da paisagem urbana do Rio de Janeiro, onde a escravidão negra se revelava com traços marcantes, transformaram o trabalho em uma das mais completas descrições sociais feita por um viajante do século XIX." ${ }^{11}$

Em 1848, ocorreu a chegada ao Brasil do inglês Alfred Russel Wallace, conhecido como um dos primeiros a vislumbrar o processo de seleção natural. Os resultados dessa viagem de coleta e exploração deram origem ao livro Narrative of travels on the Amazon e rio Negro, publicada em Londres, em 1853, um ano após Wallace deixar o país. O próprio Charles Darwin, durante sua famosa viagem no Beagle, também já havia aportado em terras brasilei-

\footnotetext{
${ }^{11}$ Não se pode esquecer que muitas das descrições desses intrépidos naturalistas estavam permeadas por todo o pensamento racial do século XIX. Essas teorias tornaram-se base explicativa para o mundo social, e os desenhos e descrições desses naturalistas acabaram, muitas vezes, servindo a leituras raciológicas da história do Brasil. Quanto à questão racial no Brasil, ver: VENTURA, Roberto. Estilo tropical: história cultural e polêmicas literárias no Brasil. São Paulo: Cia das Letras, 1991; ver também ARENDT, Hannah. Origens do totalitarismo: antissemitismo, imperialismo e totalitarismo. São Paulo: Cia das Letras, 1998.
} 
REVISTA DE HISTÓRIA

SÃO PAULO, N 167, p. 295-320,

JULHO / DEZEMBRO 2012
MARCELO LAPUENTE MAHL

Orville Adelbert Derby: notas para o estudo de sua atuação cientifico-intelectual em São Paulo (1886-1905)

ras alguns anos antes, o que reafirma o interesse dos cientistas pelo mundo natural brasileiro. ${ }^{12}$

A expedição Tayer, chefiada pelo suíço Louis Agassiz, então professor de Cambridge, em 1865, foi outro momento importante para a história dessas atividades científicas no Brasil. Com os dados coletados, Agassiz publicou, em colaboração com sua esposa, Elisabeth Cary Agassiz, o livro A journey in Brazil, em 1868, com descrições do meio natural e das práticas culturais e sociais de várias tribos amazônicas. ${ }^{13}$ Acompanhando a expedição estava Charles Frederick Hartt, aluno de Agassiz em Cambridge, e que acabou dedicando boa parte de sua vida ao Brasil. Geólogo de formação, Hartt conseguiu, após o encerramento dessa primeira exploração, outro grande financiamento nos Estados Unidos, organizando uma nova viagem ao país, agora nomeada de Expedição Morgan, devido ao patrono incentivador da empreitada. Como afirma Silvia Figuerôa (1997), foi a dedicação e a perseverança de Hartt que levaram o imperador d. Pedro II a autorizar a formação, em 1874, da Comissão Geográfica e Geológica do Império, um marco na exploração do território, com recursos e iniciativa nacional. ${ }^{14}$

\footnotetext{
${ }^{12}$ A respeito dos debates relativos aos conceitos de evolução, seleção natural e luta pela sobrevivência, expostos para o mundo científico no livro A origem das espécies, e algumas das principais controvérsias que tais ideias incitaram, consultar: BLANC, Marcel. Os herdeiros de Darwin. São Paulo: Ed. Scritta, 1994; HELLMAN, Hal. Grandes debates da ciência-dez das maiores contendas de todos os tempos. São Paulo: Ed. Unesp, 1999.

13 O principal objetivo de Agassiz no Brasil foi recolher material, principalmente peixes da região amazônica, que pudessem servir como prova científica de suas teses criacionistas, refutando assim o evolucionismo de Charles Darwin, que começava a se consolidar nos meios acadêmicos. Ao lado dessas pesquisas zoológicas, o naturalista suíço aproveitou sua estada no Brasil para empreender estudos antropológicos com a população brasileira. Em Manaus, montou um estúdio fotográfico, onde retratou tipos físicos brasileiros, principalmente índios, negros e mestiços. Tais imagens serviram, aos olhos de Agassiz, para confirmar suas teses de degenerescência produzida pela mestiçagem indiscriminada; afirmação fundamentada nas teorias raciais vigentes no período (KURY, 2001).

${ }^{14}$ Esta não foi a primeira tentativa do gênero no país. Entre 1859 e 1861, por iniciativa do Instituto Histórico e Geográfico Brasileiro, entrou em atividade a Comissão Científica de Exploração, com o objetivo de fazer o mapeamento das províncias do Norte e Nordeste. Nomes de destaque do IHGB se envolveram no projeto, como Francisco Freire Alemão, botânico do Museu Nacional, ou o poeta romântico Antonio Golçalves Dias, que ficou responsável pelos apontamentos etnográficos e pela elaboração da narrativa descritiva da viagem. Entretanto, a Comissão acabou se revelando um desastre, tanto por problemas de relacionamento entre os membros quanto pela falta de planejamento e organização da expedição, apesar do apoio de d. Pedro II e das verbas liberadas para a jornada. Em meio às críticas e ao escárnio da imprensa carioca, que, devido às inúmeras polêmicas, inclusive de ordem moral, apelidou a aventura de "Comissão das Borboletas", o grupo foi dissolvido, recolhendo, contudo, uma boa coleção
} 
A aprovação da Comissão Geográfica e Geológica aconteceu em um momento de grande expansão agrícola do país, impulsionada pela cafeicultura, que já avançava, partindo do Rio de Janeiro, em direção ao interior do estado de São Paulo e ao sul de Minas (Costa, 1998; Beiguelman, 2005). A demanda pelo conhecimento de novas áreas agricultáveis, assim como pelos tipos de solo disponíveis no Brasil, além da elaboração de cartas geológicas e mapas, facilitou o trabalho de Hartt em convencer Pedro II a financiar o projeto. O geólogo norte-americano também soube interpretar essas novas perspectivas econômicas, uma vez que sua proposta para a comissão seguia os padrões dos serviços geológicos (geological surveys), que apresentavam um direcionamento das pesquisas para os resultados práticos, com levantamento de solos e estudos que favoreciam o avanço econômico. Em outras palavras, o sucesso do modelo, utilizado também em vários países europeus no século XIX, explica-se pela união entre "ciência e aproveitamento dos recursos naturais" (Figuerôa, 2001, p. 114).

Aparentemente, a demora da Comissão em apresentar resultados práticos além do acesso limitado de Hartt ao imperador levaram ao encerramento dos trabalhos em junho de 1877, pouco mais de dois anos após o início de suas atividades. Os materiais coletados e organizados por Hartt e seus colaboradores acabaram sendo enviados ao Museu Nacional (Figuerôa, 1997). Charles Frederick Hartt ficou extremamente abalado com a dissolução da Comissão, o que pode ter favorecido sua morte no ano seguinte, que ocorreu no Rio de Janeiro, em 18 de março de 1878. Enterrado no cemitério S. Francisco Xavier, teve seus restos mortais transladados para a cidade de Buffalo, nos Estados Unidos, em 1882. Apesar da morte repentina do geólogo, com apenas 38 anos, vários de seus colaboradores científicos mantiveram laços com o Brasil. Entre eles, um de seus parceiros mais próximos, Orville A. Derby, que iniciaria então uma longa, produtiva e também conflituosa vida intelectual no Brasil.

\section{II}

O ano de 1869 foi decisivo na vida de Orville Adelbert Derby. ${ }^{15}$ Recém-matriculado na prestigiada Universidade de Cornell, em Ithaca (Estados

de objetos de mineralogia e botânica, vindas principalmente do Ceará, que fortaleceram o acervo do Museu Nacional (LOPES, 1997; KURY, 2009).

15 Apesar dos esforços de alguns pesquisadores, as informações sobre a vida de Derby ainda carecem de pesquisas mais específicas, principalmente em busca de documentação fora do país. 
Unidos), onde cursou geologia, Derby foi convidado pelo professor Hartt para acompanhá-lo ao Brasil. Aparentemente, o convite surgiu do empenho demonstrado por Derby como estudante em Cornell. Daí nasceria um relacionamento de amizade e parceria intelectual entre os dois geólogos, que só acabaria com a morte de Hartt, em 1878.

Até então, Derby não tivera nenhum contato mais próximo com o Brasil. Nascido em 23 de julho de 1851, na pequena cidade de Kelloggsville, no estado de Nova York, passou sua infância em Finger Lakes, próximo de sua cidade natal. Aí também fez seus estudos preparatórios, na Albany Normal School, ingressando finalmente em Cornell em 1869. Graduou-se em geologia em 1873, tendo concluído sua tese de doutorado no ano seguinte, utilizando-se dos conhecimentos adquiridos em suas viagens ao Brasil, fruto de sua participação nas duas expedições Morgan, das quais fizera parte, junto com F. Hartt, entre os anos de 1870 e $1871 .^{16}$ Entre os anos de 1873 e 1875, Derby continuou na universidade de Cornell, agora como instrutor de geologia e paleontologia. Apesar da pouca idade - vinte e dois anos -, ele já conquistava espaço na conceituada universidade, chegando a dar aulas como substituto de Hartt em 1874, posição que revela a força do capital simbólico e de seu círculo de relações, em boa parte conquistado em suas andanças pelo Brasil. Em dezembro de 1875, mais uma vez a convite de Hartt, Orville A. Derby retorna pela terceira vez ao Brasil, agora integrando a recém-instalada Comissão Geológica do Império. Além dos dois amigos, fizeram parte da Comissão, entre outros, Richard Rathbun, geólogo também da Universidade de Cornell; John Casper Branner, do Departamento de Botânica e Geologia da Universidade de Indiana, um dos mais próximos amigos de Derby; e o fotógrafo Marc Ferrez, um dos pioneiros da fotografia no Brasil.

\footnotetext{
As notas biográficas aqui apresentadas tiveram como fontes principais: BRANNER, J. C. Notas biographicas de geólogos. In: Revista do Brasil, n 80, 1922; Orville A. Derby 1851-1951 - alguns aspectos de sua obra. Rio de Janeiro: Divisão de Geologia e Mineralogia, 1951; FIGUERÔA, Silvia. As ciências geológicas no Brasil: uma história social e institucional 1875-1934. São Paulo: Ed. Hucitec, 1997; LAMEGO, Alberto Ribeiro. Derby, o sábio incompreendido. In: Boletim Geográfico, n 103. 1951; LEONARDOS, Othon Henry. A mineralogia e a petrografia no Brasil. In: AZEVEDO, Fernando. As ciências no Brasil, vol. 1. São Paulo: Ed. Melhoramentos, 1955, p. 267-313; TOSATTO, Pierluigi. Orville Adelbert Derby. "O pai da geologia do Brasil". Rio de Janeiro: CPRM, PNPM, 2001. Informações importantes também foram compiladas e publicadas no Dicionário histórico-biográfico das ciências da saúde no Brasil (18321930), da Fiocruz (disponível em www.dichistoriasaude.coc.fiocruz.br). Acesso em 7/10/ 2011.

16 O título da tese foi "On the carboniferons brachiapoda of Itaituba, rio Tapajoz", e foi publicada nos boletins da Universidade de Cornell, em 1874.
} 
Durante os dois anos de atividades da Comissão, Derby teve a oportunidade de expandir seus conhecimentos sobre o território brasileiro. Conheceu a Bahia, viajou pelo rio São Francisco, além de retornar à região Norte (Amazonas e Pará). A extinção da Comissão, em 1877, apesar do empenho de Hartt em reverter a decisão, tomada pelo ministro dos Negócios da Agricultura, João Lins Vieira Cansanção de Sininbu, com o aval de d. Pedro II, fez com que muitos dos membros originais voltassem aos Estados Unidos, como Rathbun e Branner. Derby, entretanto, continuou em terras nacionais, mesmo após a morte de Hartt, em 1878.

Com o final da Comissão Geológica do Império e a morte de Hartt, Derby começou a trilhar seu próprio caminho. Entre os anos de 1877 e 1886, o geólogo norte-americano exerceu várias funções, atendendo tanto interesses governamentais quanto privados. Trabalhou no Museu Nacional, sem remuneração fixa, até ser nomeado oficialmente chefe da $3^{0}$ seção de Geologia. Colaborou com o museu até 1890, desenvolvendo atividades de pesquisa, catalogação e organização de coleções. Também realizou trabalhos na bacia do São Francisco, no Rio de Janeiro, Minas Gerais, São Paulo e Paraná.

O grande número de projetos em que se envolveu revela que Derby não teve dificuldades em manter suas atividades profissionais no Brasil, mesmo após a morte de Hartt e o fim da Comissão Geológica do Império. Tornara-se um exímio e agora experiente geólogo, além de conhecer profundamente muitas das regiões mais recônditas do país, em um momento de pleno desenvolvimento da agricultura nacional, que demandava conhecimentos cada vez mais aprofundados em sua área original de formação.

Em 1879, fez parte da Comissão Hidráulica do Império, chefiada por William Milnor Roberts, criada para explorar o rio São Francisco. Pouco mais de um ano depois, trabalhou com Claude Henri Gorceix, diretor da Escola de Minas de Ouro Preto, na elaboração de cartas geológicas indicativas de Minas Gerais. Muito ativo intelectualmente, Derby publicou artigos nas áreas de mineralogia, petrografia e paleontologia. Definitivamente, sua vida profissional havia se consolidado no Brasil.

Em 1885, Orville Derby respondeu ao pedido feito pelo presidente da província de São Paulo, João Alfredo Correa de Oliveira, para a elaboração de um plano de exploração geológica da província paulista. O projeto foi adaptado dos trabalhos que Hartt havia feito para a Comissão Geológica do Império e, aparentemente, chamou a atenção dos governantes, principalmente no que se refere à promessa da elaboração de uma carta geológica regional. Naquele momento, o estado de São Paulo estava em ampla expansão agrícola, impulsionada pelo desenvolvimento cafeeiro por todo o seu 
território. Na região oeste, a cidade de Ribeirão Preto já aparecia como área de importância econômica vital, e a região noroeste, com a cidade de Araraquara como ponto culminante, revelava-se promissora para a agricultura (Marcílio, 2000; Monbeig, 1984).

Havia, portanto, uma demanda por conhecimentos geológicos que pudessem respaldar tecnicamente essa expansão, ainda majoritariamente cafeeira, e os trabalhos de Derby respondiam a tais interesses. Em 1886, sob sua chefia, é instalada oficialmente a Comissão Geográfica e Geológica de São Paulo. Este momento pode ser indicado como o auge de seu prestígio pessoal e profissional, uma vez que dirigia um grupo de profissionais indicados e liderados por ele, trabalhando para os interesses da província que já havia se tornado a mais importante área econômica do país. O geólogo transfere-se do Rio de Janeiro para São Paulo, e inicia uma nova fase de sua vida em terras brasileiras.

Agora morando na capital paulista, Derby formou um novo grupo de trabalho, unindo antigos colaboradores com novos quadros técnicos. Um dos mais próximos foi o engenheiro Theodoro Fernandes Sampaio. Eles trabalharam juntos pela primeira vez em 1879, na expedição científica ao vale do São Francisco. A partir daí, tornaram-se amigos e companheiros de andanças exploratórias. ${ }^{17}$ Sampaio é autor de uma vasta obra que extrapolou os limites da engenharia e da geografia, publicando trabalhos nas áreas de história, etnografia e etimologia (Santos, 2010). Também dois engenheiros formados na Escola de Minas de Ouro Preto, Luis Felipe Gonzaga de Campos e Francisco de Paulo Oliveira, integravam a Comissão.

As atividades do grupo originaram uma grande coleção de geologia, além de uma série de artefatos etnográficos recolhidos durante as missões exploratórias. Com o intuito de tornar público esse imenso material, Derby propôs ao governo a criação do museu da CGGSP, o que acabou por originar o Museu Paulista. O primeiro diretor do museu foi o zoólogo Friedrich Albrecht Von Ihering, que chegou a São Paulo por indicação do próprio Derby, em 1893, para assumir a direção da seção de zoologia da Comissão. Ao longo dos anos, Ihering foi o responsável por transformar a revista do Museu Paulista em um dos mais prestigiados periódicos das ciências naturais no Brasil, apesar das controvérsias que deflagraram seu afastamento do museu em 1916.

\footnotetext{
${ }^{17}$ O geógrafo José Veríssimo da Costa Pereira (1955) destaca a importância da Comissão Geográfica e Geológica de São Paulo para o desenvolvimento dos conhecimentos e das pesquisas geográficas no Brasil, uma vez que os estudos liderados por Orville A. Derby forneceram uma importante base para a compreensão da geografia física e da geomorfologia nacional.
} 
Atuando pelo desenvolvimento das ciências naturais em São Paulo, Derby também ajudou, juntamente com Francisco Ramos de Azevedo e o botânico sueco Alberto Löfgren, na criação do Horto Botânico, que mais tarde daria origem ao Instituto Florestal de São Paulo. No mesmo ano, o chefe da CGGSP planejou a criação Serviço Florestal Paulista. Entretanto, sua atuação não ficou restrita às ciências naturais. Ele fez parte do grupo fundador do Instituto Histórico e Geográfico de São Paulo, que começou suas atividades em 1894. O IHGSP era formado principalmente por membros da elite econômica, política e cultural paulista. Nas revistas do instituto, Derby pode exercitar sua curiosidade intelectual, publicando artigos na área de história, geografia e etnografia. ${ }^{18}$ Nessa agremiação, ele pode conviver de forma mais direta com boa parte das personalidades influentes da vida política paulista, além de estar inserido em um espaço de destacado prestígio intelectual, posição desfrutada pelo instituto pelo menos até a década de 1930 (Ferreira, 2002; Mahl, 2001). Entretanto, mesmo essa facilidade de circulação entre as elites paulistanas não impediu que Derby se envolvesse em uma controvérsia que acabaria enfraquecendo sua posição nos meios intelectuais da capital.

Como explica Silvia Figuerôa (1997), a saída de Derby da Comissão Geológica de São Paulo começou a se desenhar a partir das críticas levantadas por Francisco Bhering, então professor da Escola Politécnica de São Paulo. Afora questões de ordem técnica apontadas pelo professor da Politécnica, que questionou os métodos utilizados pelo norte-americano em seus trabalhos geológicos, o grande desgaste se originou pela demora na divulgação dos trabalhos efetuados, principalmente em relação ao atraso na entrega da carta geológica completa do estado, uma das promessas mais aguardadas pelo governo de São Paulo. ${ }^{19}$ Os debates empreendidos na imprensa aca-

${ }^{18}$ Após se estabelecer na cidade do Rio de Janeiro, em 1877, Derby passou a colaborar nas revistas do Instituto Histórico e Geográfico Brasileiro, onde muitos de seus colegas atuavam, já esboçando um tipo de curiosidade intelectual que viria exercer, de forma plena, tempos depois, no Instituto Histórico e Geográfico de São Paulo.

${ }^{19}$ Em 1910, a Revista do Instituto Histórico e Geográfico de São Paulo publicou uma conferência realizada pelo sócio da agremiação, Gentil de Assis Moura, que produziu, ao longo de sua vida intelectual, várias obras sobre a história paulista. Nela, o autor indica o estágio em que se encontravam os trabalhos da Comissão, no que se referia à carta geológica do estado. Suas palavras também nos fornecem dados importantes sobre o projeto de Derby e o quanto ele era complexo, amplo e de difícil execução: "Em S. Paulo, como marco milliario para as explorações modernas, cria-se em 1886 a Commissão Geographica e Geológica que Orville Derby organiza e que João P. Cardoso prosegue com a mesma dedicação - e que se incumba de levantar a carta da Provincia na escala de 1:100.000 com representação da configuração 
baram por desgastar a imagem pública e a posição política do diretor, que acabou por se demitir da Comissão Geográfica e Geológica em 1905. Outra questão pertinente, que ajuda a compreender o seu desgaste em meio ao governo paulista, refere-se ao confronto entre duas visões de ciência que, naquele momento, ainda dividiam o espaço acadêmico: de um lado, uma percepção mais romântica, tributária dos naturalistas do século XIX. De outro, a praticidade dos novos engenheiros e técnicos, então representados pela Escola Politécnica. Orville A. Derby, formado naquela primeira concepção, seguia um ritmo mais lento, ao mesmo tempo em que nutria interesses mais plurais, explicitados em sua própria obra diversificada e abrangente, que versava da história indígena às origens do povo paulista. Aparentemente, sua ciência não conseguia mais concorrer com a emergência das novas demandas econômicas, cada vez mais rápidas e exigentes de resultados práticos imediatos. Ainda segundo Figuerôa (1997):

A visão naturalista de Derby acabou, entretanto, por confrontar-se com os interesses mais imediatos das elites e do poder público de São Paulo. Após quase vinte anos de trabalho, a CCG ainda não havia cumprido sua principal tarefa, explícita desde sua criação em 1886 - o chamado sertão de São Paulo - como era conhecida uma vasta região a oeste do Estado, que compreendia quase um terço do território - não se encontrava mapeado a fim de viabilizar sua ocupação e exploração. Em 1899 foram publicados os três primeiros mapas, saindo à luz mais catorze até 1905, sem, porém, contemplar a região mais a oeste (p. 171).

Apesar do desgaste com o processo de desligamento da Comissão, ele rapidamente retomou suas atividades. Sua rede de contatos agiu novamente e, ainda em 1905, foi convidado, pelo secretário de Agricultura, Miguel Calmon Du Pin e Almeida, para trabalhar na Bahia, onde passou a dirigir o Serviço de Terras e Minas do Estado. Porém, sua permanência em Salvador não foi longa. Em 1907, Derby volta ao Rio de Janeiro para reorganizar o Serviço Geológico e Mineralógico do Brasil. Ele formou uma nova equipe de trabalho, que agora contava com o engenheiro Miguel Arrojado Lisboa, além de

do terreno por meio de curvas de nível equidistantes de 25 metros e que se encarrega egualmente do estudo da Geologia, da Flora e da Meteorologia. O trabalho elaborado nas 23 das suas folhas publicadas, realizado no numero elevado das suas expedições e mencionadas em relatorios minuciosos ou descriptos nos boletins que se referem á Botanica, Antthopologia, Ethnographia, Meteorologia, Mineralogia, Geologia e Geographia, o seu trabalho digo, não pode ser senão enumerado por quem delle foi o ultimo dos operários (...)" (MOURA, 1910, p. 215). 
Francisco de Paulo Oliveira e Luiz Felipe de Gonzaga de Campos, estes dois últimos antigos companheiros oriundos da Comissão Geológica Paulista.

Contudo, as mesmas cobranças por resultados práticos que aconteceram em São Paulo voltaram a dificultar sua vida no Rio de Janeiro, agora comandando o Serviço Mineralógico do Brasil. A partir de 1910, a pressão sobre o serviço fica evidente, quando ocorre uma diminuição tanto no orçamento quanto nos salários dos funcionários. Derby passa a se sentir desprestigiado e insatisfeito, situação que piora com o início da Primeira Guerra Mundial, em 1914. O conflito foi usado como justificativa, pelo então ministro da Agricultura, Indústria e Comércio, José Rufino Bezerra Cavalcante, para uma diminuição ainda maior nos gastos com a seção.

Foi em meio a tantas dificuldades que ocorreu o suicídio de Orville Adelbert Derby em um quarto de hotel na cidade do Rio de Janeiro, em 1915, alguns meses depois de se naturalizar brasileiro. Após mais de quarenta anos dedicados à ciência nacional, morreu mais brasileiro que norte-americano um dos filhos diletos da Universidade de Cornell. ${ }^{20}$

\section{III}

A vida de Orville A. Derby no Brasil coincidiu com um momento de profundas transformações no país, que podem ser observadas, de forma sintética, nas mudanças na estrutura econômica brasileira, deflagradas pelo desenvolvimento da cafeicultura, resultando em uma modernização conservadora; nas agitações republicanas e abolicionistas, influenciadas pelo debate positivista e evolucionista, presentes no fim do Império e no início da República; na maior diversificação social, fruto do grande afluxo de imigrantes que direcionavam-se tanto para o campo quanto para as cidades; e nos movimentos culturais refletindo sobre esse novo mundo onde as máquinas, o discurso científico e a vida urbana tornavam-se cada vez mais influentes, povoando os sonhos e os projetos de modernidade das elites.

${ }^{20}$ José Veríssimo da Costa Pereira (1955) também destacou a contradição entre uma ciência menos voltada para resultados práticos e as emergentes demandas econômicas como um dos fatores que contribuíram para derrocada de Derby no Serviço Geológico e Mineralógico. Segundo o autor, "No tempo de Derby (1907-1915), o lado mais econômico nas pesquisas vinha apenas em caráter subsidiário (...)" (p. 369). Mais uma vez, seu perfil de naturalista, formado no século XIX, não se ajustou às necessidades daqueles novos e frementes, segundo expressão de Nicolau Sevcenko (2000), tempos nacionais. 
Este geólogo norte-americano destacou-se na vida científica e cultural do Brasil nesse momento em que tantas mudanças fundamentais sucediam. Seu nome alcançou prestígio nos meios nacionais e internacionais, e ele participou ativamente, não somente como cientista, mas também como articulador político do processo de institucionalização das ciências naturais (com destaque para a geologia) no Brasil, atuando em locais como o Museu Paulista e o Museu Imperial, formando e organizando coleções ou lutando por recursos financeiros frente aos gabinetes governamentais (Figuerôa, 1997; Lopes, 1997). Entretanto, a profícua carreira como geólogo foi somente uma das vertentes de sua atuação intelectual. Mais precisamente durante os anos de trabalho em São Paulo, ele embrenhou-se em meios estranhos ao campo da geologia, quando desfrutou do convívio da elite paulista, em um momento em que o estado e a própria cidade de São Paulo buscavam espaço no cenário nacional, impulsionados pela força econômica trazida pela riqueza da cafeicultura.

O café foi o grande responsável pela mudança na história da cidade de São Paulo. A estrada de ferro que, em 1868, ligou a capital paulista à cidade de Santos trouxe novo vigor ao até então acanhado povoado. A partir daí, ferrovias foram construídas rumo às novas regiões agrícolas do interior; e a cidade de São Paulo transformou-se no centro administrativo dessa expansão do capital. Chegaram os bancos e as casas financeiras, centros de distribuição de mercadorias e equipamentos, empresas de exportação e todos os demais empreendimentos e órgãos necessários para a expansão da cafeicultura. A cidade passou a exercer um forte poder de atração para essas novas elites, em grande parte oriundas do próprio interior paulista (Holanda, 1995).

Espaços para uma incipiente vida cultural começaram a se formar, instituições de ensino se seguiram a já consagrada academia de Direito, e novos grupos intelectuais se estabelecem na capital. Exemplo dessa nova elite são os irmãos Prado (Antonio, Martinico e Eduardo) que, em meio a riqueza e a pujança do café plantado no interior do estado, tornaram-se figuras de destaque no cenário político regional e nacional. Antonio Prado (1840-1929) foi prefeito de São Paulo, entre os anos de 1899 e 1910. Seu irmão, Martinico, supervisionou as primeiras levas de imigrantes que chegaram para trabalhar nas fazendas de café do interior. Eduardo foi um dos mais ativos incentivadores da vida intelectual paulista, além de manter uma intensa atividade literária e jornalística na capital do estado. Antonio, Martinico e Eduardo fizeram parte de uma geração que contava com nomes como os de Joaquim Nabuco e Rui Barbosa, todos personagens que influenciaram fortemente a política brasileira na virada do século XIX (Morse, 1970). 
Essas novas elites cafeeiras, que chegavam cada vez mais alto nos quadros políticos federais principalmente a partir da proclamação da República, não tardaram em incrementar e investir recursos financeiros na vida cultural paulistana. Assim como no Rio de Janeiro, livrarias, avenidas para o footing, bares e cafeterias serviam como ponto de encontro nesses novos tempos de novos homens (Sevcenko, 2000). As viagens para a Europa de muitos desses endinheirados do café ajudavam a dinamizar a vida cultural da cidade. Na ausência de espaços próprios, os saraus domésticos tornavam-se um ponto de encontro de homens que direcionavam um olhar curioso para fora do país. O mais famoso desses espaços privados, que se transformaram em verdadeiras academias informais, foi a chácara de Veridiana Valéria da Silva Prado, a dona Veridiana, no bairro Higienópolis. Matriarca da família Prado, recebeu em sua residência, junto com seus filhos, muitos letrados da época, em meio a jantares e discussões que animavam a vida cultural paulistana. Nesse ambiente cosmopolita e ao mesmo tempo familiar, Eduardo Prado foi um dos mais presentes, convivendo com Rui Barbosa, barão do Rio Branco, Joaquim Nabuco e Capistrano de Abreu. Fora do país, Eduardo também teve uma vida cultural bastante ativa. Seu apartamento, na rue de Rivoli, em Paris, tornou-se um importante ponto de encontro da elite intelectual brasileira na capital francesa, além de ser frequentado também por personalidades literárias europeias, com destaque para Eça de Queiroz (Lyra, 1965).

Outro nome que não pode ser esquecido foi o de Fretias Valle, que transformou sua chácara na Vila Mariana em outro ponto de encontro da intelectualidade paulista. Em meio a jantares, música e dança, o mentor e anfitrião da illa Kyrial conseguiu estimular discussões a respeito das formas e expressões artísticas então em voga, em um momento em que conviviam, nem sempre em harmonia, parnasianistas, simbolistas, românticos e as vanguardas europeias. Seu papel aglutinador de nomes e tendências artísticas o posiciona como um dos que contribuíram de forma decisiva para a efervescência do movimento modernista em São Paulo; vale lembrar sua participação na organização da Semana de Arte Moderna de 1922, um dos marcos do modernismo nacional (Camargos, 2001).

Durante o período em que morou e atuou na Comissão Geográfica e Geológica, entre os anos de 1886 e 1905, Derby moveu-se com desenvoltura em meio a esses círculos letrados, construindo o que Jean-François Sirinelli (2003; 1996) e Pierre Bourdieu $(1998 ; 2008)$ chamam de uma rede de sociabilidade bastante atuante e influente, não somente nas esferas culturais e intelectuais regionais, como também no próprio mundo político e social que extrapolava as fronteiras do estado. Um dos seus mais próximos amigos foi Eduardo 
Prado. Conheceram-se provavelmente pelas mãos de Teodoro Sampaio, outro participante assíduo dos grupos intelectuais paulistas. Derby também logrou da amizade de dona Veridiana, que mantinha sua casa aberta para o geólogo norte-americano, que acabou tornando-se convidado constante dos concorridos jantares da família Prado (Motta Filho, 1967). Esse contato estreito com esses grupos levou Derby ao Instituto Histórico de São Paulo, do qual foi um dos fundadores. Nesta agremiação, ele contribuiu ativamente para a construção de uma visão laudatória da história paulista, escrevendo artigos de história e etnografia, seguindo os modelos de exaltação da história regional, próprios desse tipo de instituição, na virada do século XIX. ${ }^{21}$

Foi durante a sua experiência paulista, quando circulava pelas esferas intelectuais da capital do estado e participava ativamente das atividades do IHGSP que estreitou relações com o escritor Euclides de Cunha. A obra máxima de Euclides, Os sertões, que geralmente é classificada por grande parte da crítica literária como uma obra híbrida, ${ }^{22}$ transitando entre a literatura e a ciência, contém referências aos trabalhos de Derby, principalmente sobre seus estudos da geologia brasileira. Durante o período de elaboração da obra, entre os anos de 1897 e 1901, Euclides manteve um contato muito próximo com o geólogo; eles se visitaram tanto em São José do Rio Pardo, onde Euclides trabalhava no momento de elaboração do livro, quanto em São Paulo, onde Derby mantinha uma chácara como residência (Andrade, 1960). Também estavam juntos quando Euclides leu uma parte de sua ainda inacabada obra no Instituto Paulista, fato que foi muito comemorado entre os sócios do IHGSP, e que acabou influenciando a própria produção historiográfica da agremiação (Ferreira, 2002; Santana, 2001).

\footnotetext{
${ }^{21}$ Os vários institutos históricos e geográficos fundados no Brasil, na transição do século XIX para o século $\mathrm{XX}$, possuíam um forte traço regional, buscando enaltecer valores próximos das elites intelectuais que, predominantemente, formavam seus quadros associativos, construindo aí histórias e identidades singulares arduamente enaltecidas e defendidas por seus seletos integrantes (Ferreira; Mahl, 2011; Schwarcz, 1993).

${ }^{22}$ Muitas das análises mais conhecidas sobre o livro Os sertões partem dessa premissa; de que se trata de uma obra que transita entre a literatura, no seu estilo e na forma de construção da narrativa, e as afirmações de teor científico, dialogando, em linhas gerais, com os paradigmas cientificistas da época em que foi escrita. Nesta linha de raciocínio, pode-se citar desde o trabalho pioneiro de Olímpio de Sousa Andrade, História e interpretação dos sertões (1960), até estudos mais recentes, como o livro inacabado de Roberto Ventura, Euclides de Cunha (2003), ou Euclides da Cunha: uma odisseia nos trópicos (2009), escrito por Frederic Amory. Entretanto, críticos como Luis Costa Lima (2006) não concordam com a ideia de hibridismo da produção euclidiana, preferindo apontar para uma visão mais ampla de literatura, e uma separação menos rígida entre literatura e história.
} 
REVISTA DE HISTÓRIA SÃO PAULO, N ${ }^{\circ} 167$, p. 295-320,

JULHO / DEZEMBRO 2012
MARCELO LAPUENTE MAHL

Orville Adelbert Derby: notas para o estudo de sua atuação científico-intelectual em São Paulo (1886-1905)

Os conhecimentos sobre a constituição geológica do país devem ter facilitado a aproximação dos dois, uma vez que Derby era então considerado um dos maiores conhecedores dos sertões brasileiros, experiência adquirida em tantas andanças pelo interior do país. Euclides, como boa parte dos intelectuais de seu tempo, valorizava as relações entre o homem e o meio como um dos aspectos fundamentais para a constituição social e os vastos conhecimentos geológicos do amigo norte-americano contribuíram para fortalecer os argumentos científicos explicitados em Os sertões (Amory, 2009; Santana, 2001).

Foi ao longo desse momento de contato estreito com várias figuras atuantes do meio intelectual paulista que Derby produziu uma obra que se afastou da geologia, expandindo seus interesses para a história, a geografia e os estudos etnográficos. Em conjunto com Teodoro Sampaio, seu grande parceiro nesse momento, ou mesmo individualmente, produziu uma série de artigos discorrendo sobre a história de São Paulo, em seus aspectos econômicos, sociais e étnicos.

Se, por um lado, essa enorme ambição intelectual, que rompia com as limitações da especificidade científica, foi uma das causas de seu declínio, ela também lhe abriu as portas da vida social e científica paulista, campo fértil para a valorização de seus diversificados conhecimentos, que respondiam tão bem aos anseios de distinção dessas elites que ascendiam e se destacavam cada vez mais no cenário nacional. A estas, que durante algum tempo Ihe acolheram entusiasticamente, Orville Adelbert Derby retribuiu, conscientemente (ou não), de uma forma que se revelou perene e vigorosa, empregando seu prestígio pessoal na fundação e consolidação do Instituto Histórico e Geográfico de São Paulo, um dos espaços privilegiados de gestação de toda a mítica bandeirante que ainda pode ser reconhecida nos dias atuais.

\section{Referências bibliográficas}

AMORY, Frederic. Euclides de Cunha - uma odisseia nos trópicos. São Paulo: Ateliê Editora, 2009.

ANDRADE, Olímpio de Sousa. História e interpretação de “Os sertões". São Paulo: Edart, 1960.

ARENDT, Hannah. Origens do totalitarismo. Trad. Roberto Raposo. São Paulo: Cia das Letras, 1998.

AZEVEDO, Fernando. A cultura brasileira. Brasília: UNB, 1963

. As ciências no Brasil, vol. 1 e 2. São Paulo: Ed. Melhoramentos, 1955.

BEIGUELMAN, Paula. A formação do povo no complexo cafeeiro. São Paulo: Edusp, 2005.

BLANC, Marcel. Os herdeiros de Darwin. Trad. Mariclara Barros. São Paulo: Ed. Scritta, 1994. 
BOURDIEU, Pierre. O poder simbólico. Trad. Fernando Tomaz. Rio de Janeiro: Bertrand Brasil, 1998.

As regras da arte. Gênese e estrutura do campo literário. Trad. Maria Lucia Machado. São Paulo: Cia das Letras, 2002.

A distinção - crítica social do julgamento. Trad. Daniela Kern; Guilherme J. F. Teixeira. São Paulo: Edusp, 2008.

BRANNER, J. C. Notas geográphicas de geólogos. Revista do Brasil. São Paulo, vol. 80, agosto de 1922.

BREFE, Ana Cláudia Fonseca. O Museu Paulista - Affonso de Taunay e a memória nacional (1917-1945). São Paulo: Ed. Unesp, 2005.

CAMARGOS,Márcia. Villa Kyrial-crônica da BelleÉpoquepaulistana. SãoPaulo:Ed.Senac, 2001.

COSTA, Emília Viotti da. Da senzala à colônia. São Paulo: Editora Unesp, 1998.

DANTES, Maria Amélia M. Espaços da ciência no Brasil 1800-1930. Rio de Janeiro: Fiocruz, 2001.

Dossiê 1: Os Institutos Históricos e Geográficos. Revista Patrimônio e Memória. Cedap, vol. 7, $\mathrm{n}^{\mathrm{o}}$ 1, junho de 2011. Disponível em www.cedap.assis.unesp.br

FERREIRA, Antonio Celso. A epopeia bandeirante: letrados, instituições, invenção histórica (1870-1940). São Paulo: Ed. da Unesp, 2002.

FERREIRA, Antonio Celso; MAHL, Marcelo Lapuente. Preservação e patrimônio no Instituto Histórico e Geográfico de São Paulo (1894-1937). Revista Patrimônio e Memória, vol. 7, $\mathrm{n}^{\mathrm{o}}$ 1, jun. 2011, p. 3-18.

FIGUERÔA. As ciências geológicas no Brasil: uma história social e institucional, 1875-1934. São Paulo: Hucitec, 1997.

A Comissão Geológica do Império do Brasil. In: DANTES, Maria Amélia M. Espaços da ciência no Brasil 1800-1930. Rio de Janeiro: Fiocruz, 2001.

FOUCAULT, Michel. As palavras e as coisas - uma arqueologia das ciências humanas. Trad. Salma Tannis Muchail. São Paulo: Martins Fontes, 1987.

FRANÇA, Jean Marcel Carvalho; RAMINELLI, Ronald. Andanças pelo Brasil colonial. São Paulo: Unesp, 2009.

FRANÇA, Jean Marcel Carvalho. Visões do Rio de Janeiro colonial. Rio de Janeiro: José Olympio, 2008.

FREITAS, Marcus Vinícius de. Charles Frederick Hartt, um naturalista no Império de d. Pedro II. Belo Horizonte: Ed. UFMG, 2002.

GAGLIARDI, José Mauro. O indígena e a República. São Paulo: Hucitec, Edusp, Secretaria de Cultura do Estado de São Paulo, 1989.

GOMES, A. M. C. História e historiadores: a política cultural do Estado Novo. Rio de Janeiro: FGV, 1986.

GUIMARÃES, M. L. S. Nação e civilização nos trópicos: O Instituto Histórico e Geográfico Brasileiro e o projeto de uma história nacional. Estudos Históricos. Rio de Janeiro, vol. 1, 1988.

HEIZER, Alda; VIDEIRA, Antonio Augusto Passos. Ciência, civilização e império nos trópicos. Rio de Janeiro: Access, 2001. 
HELLMAN, Hal. Grandes debates da ciência. Trad. José Oscar A. Marques. São Paulo: Ed. Unesp, 1999.

HOLANDA, Sérgio Buarque de. Raízes do Brasil. São Paulo: Cia. das Letras, 1995.

KURY, Lorelai. A sereia amazônica de Agassiz: zoologia e racismo na Viagem ao Brasil (1865-1866). Revista Brasileira de História. São Paulo: ANPUH, vol. 21, 2001. (org.) Comissão Científica do Império (1859-1861). Rio de Janeiro: Ed. Andrea Jakobson, 2009.

LAMEGO, Alberto Ribeiro. Derby, o sábio incompreendido. Boletim Geográfico, nº 103, 1951.

LEINZ, Viktor. A geologia e a paleontologia no Brasil. In: AZEVEDO, Fernando de. As ciências no Brasil, vol. 1. São Paulo: Ed. Melhoramentos, 1955. p. 245-263.

LEONARDOS, Othon Henry. A mineralogia e a petrografia no Brasil. In: AZEVEDO, Fernando de. As ciências no Brasil, vol. 1. São Paulo: Ed. Melhoramentos, 1955. p. 267-313.

LIMA, Luis Costa. História, ficção, literatura. São Paulo: Cia das Letras, 2006.

LYRA, Heitor. O Brasil na vida de Eça de Queiroz. Lisboa: Edição Livros do Brasil Lisboa, 1965.

LOPES, Maria Margaret. O Brasil descobre a pesquisa científica: os museus e as ciências naturais no séc. XIX. São Paulo: Hucitec, 1997.

MARCÍLIO, Maria Luiza. Crescimento demográfico e evolução agrária paulista 1700-1836. São Paulo: Edusp, 2000.

MAHL, Marcelo Lapuente. Teorias raciais e interpretação histórica: o Instituto Histórico e Geográfico de São Paulo (1894-1940). Dissertação de mestrado, História do Brasil, Departamento de História, Unesp/Assis, 2001.

MICELI, Sérgio. Intelectuais à brasileira. São Paulo: Cia das Letras, 2001.

MONBEIG, Pierre. Pioneiros e fazendeiros de São Paulo. Trad. Ary França e Raul de Andrada e Silva. São Paulo: Hucitec, 1984.

MORSE, Richard. Formação histórica de São Paulo - da comunidade à metrópole. São Paulo: Difel, 1970.

MOTTA FILHO, Cândido. A vida de Eduardo Prado. Rio de Janeiro: Ed. José Olympio, 1967.

MOURA, Gentil de Assis. A geographia nacional. Revista do Instituto Histórico e Geográfico de São Paulo. São Paulo, vol. XV, 1910. p. 211-219.

NOGUEIRA, Eliana. Uma história brasileira da botânica. Brasília: Paralelo 15, 2000.

Orville A. Derby - 1851-1951 - alguns aspectos de sua obra. Rio de Janeiro: Divisão de Geologia e Mineralogia, 1951.

PEREIRA, João Baptista Borges; SCHADEN, Egon. Exploração antropológica. In: HOLANDA, Sérgio Buarque. História geral da civilização brasileira. Tomo $2.3^{\circ} \mathrm{v}$. São Paulo/Rio de Janeiro: Difel, vol. 3, 1976.

PEREIRA, José Veríssimo da Costa. A geografia no Brasil. In: AZEVEDO, Fernando de. As ciências no Brasil, vol. 1. São Paulo: Ed. Melhoramentos, 1955. p. 317-406.

PINTO, Olivério M. Oliveira. Viajantes e naturalistas. In: HOLANDA, Sérgio Buarque. História geral da civilização brasileira. Tomo $2.3^{\circ}$ v. São Paulo/Rio de Janeiro: Difel, vol. 3, 1976. 
SANJAD, Nelson. Emílio Goeldi (1859-1917). A aventura de um naturalista entre a Europa e o Brasil. Rio de Janeiro: EMC, 2009.

SANTANA, José Carlos Barreto. Euclides da Cunha e as ciências naturais. São Paulo: Hucitec/ Universidade Estadual de Feira de Santana, 2001.

SANTOS, Ademir Pereira dos. Theodoro Sampaio - nos sertões e nas cidades. Rio de Janeiro: Versal, 2010.

SCHWARCZ, Lilia Moritz. O espetáculo das raças - cientistas, instituições e questão racial no Brasil - 1870-1930. São Paulo: Cia das Letras, 1993.

As barbas do imperador - D. Pedro II, um monarca nos trópicos. São Paulo: Cia das Letras, 2007.

SEVCENKO, Nicolau. Orfeu extático na metrópole - São Paulo, sociedade e cultura nos frementes anos 20. São Paulo: Cia das Letras, 2000.

SIRINELLI, Jean-François. A geração. In: AMADO, Janaína; FERREIRA, Marieta de Moraes. Usos e abusos da história oral. Rio de Janeiro: FGV, 1996.

Os intelectuais. In: RÉMOND, René. Por uma história política. Trad. Dora Rocha. Rio de Janeiro: FGV, 2003.

TOSATTO, Pierluigi. Orville Adelbert Derby "O pai da geologia do Brasil". Rio de Janeiro: CPRM, PNPM, 2001.

VENTURA, Roberto. Estilo tropical - história cultural e polêmicas literárias no Brasil. São Paulo: Cia das Letras, 1991. Euclides da Cunha. São Paulo: Cia das Letras, 2003 (obra póstuma). 